\title{
Perspectives on gender parity in bioanalysis: an interview with Lauren Stevenson
}

\author{
Lauren F Stevenson*,1 \\ ${ }^{1}$ Development Biomarkers and Bioanalytical Sciences, Biogen, Cambridge, MA 02142, USA \\ *Author for correspondence: lauren.stevenson@biogen.com
}

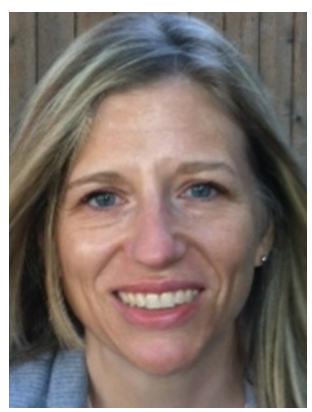

\section{Biography:}

Lauren is Senior Director, Development Biomarkers \& Bioanalytical Sciences at Biogen, Cambridge, MA, USA where she leads a team of talented scientists, setting bioanalytical and biomarker strategies and developing pharmacokinetics (PK), immunogenicity and biomarker assays in support of programs at all stages of development, from discovery to post-marketing. Lauren's team currently supports over 40 therapeutic programs, delivering PK and immunogenicity strategy and execution for Biogen's large molecule, antisense oligonucleotide (ASO0 and gene therapy portfolio as well as developing biomarkers in support of multiple sclerosis, immunology, fibrosis, rare and neurodegenerative disease indications. Externally, Lauren engages the broader industry and regulatory agencies as an invited speaker and course instructor at multiple conferences and workshops each year. In concert with her scientific role, Lauren is passionate about people development, has received certification as a Strengths coach and is active in mentorship and career development programs.

Accepted for publication: 5 March 2019; Published online: 18 April 2019

\section{What advice would you give to young women hoping to embark on a career in the field?}

My advice is the same for men and women and is applicable regardless of field. Fundamentally, it is important to be driven by your personal interests and passion and not be fixated on solely vertical trajectories. One lament I have in this field is that everyone (men and women) see promotion as commensurate with growth. As a result, people are obsessed with getting to the next level rather than thinking about whether the role is a good fit. It seems that no sooner does a promotion happen than one looks to get to the next level. Be self-aware, develop a strong understanding of what really gets you out of bed in the morning and build your career so that it feeds those motivations. This could lead you down a much less linear path, but it will most assuredly be more rewarding. If you are doing work you love every day, rather than ticking boxes to get to the next level (so you can potentially do even less of what you love to do), you will be energized, creative and open to innovation. And those things will lead to success. This is not to say that you should spurn vertical growth opportunities - but rather to make sure that any opportunity you consider is aligned with your talents, your interests and your personal values and motivations.

\section{How can mentors help women in their career development?}

Mentors are critical in providing perspectives and insights that might otherwise be missed. While your manager may provide great feedback, it will most frequently be through the lens of achieving the business goals. A mentor can more easily focus on helping you realize your best self, beyond the context of the business. While it can be very helpful to have formal mentors, I have found that by being observant, you can find informal mentors all around you. I have heard it said that the worst way to get a mentor is to seek one out. Instead, become an observer and identify those people whom you admire. Consider why you admire them and what you might learn from them and then have a conversation with them. It is also important to recognize that mentors do not need to be senior level people. Everyone, at every level, has their own unique talents. 


\section{What are the main motivations for you in the industry as a woman?}

My motivations are all grounded in a desire to help people and contribute to society in a positive way. Working in the biopharmaceutical industry provides me the opportunity to do meaningful work every day that positively impacts the lives of patients. In addition, as the leader of a team, I am also able to directly facilitate the career growth of others, so they too can broaden their impact. One of my greatest passions is to ensure that everything we do has real purpose. This leads us to challenge conventional ways of thinking and push the envelope both strategically and scientifically, which creates an engaging, exciting environment where scientists can grow, and patients benefit as a result.

\section{How did you overcome obstacles in your scientific career? Can you share any useful information others can use in their own careers?}

I have frequently said "The science is easy. People are complex." The importance of relationships and collaboration cannot be overstated in our field. Most of the significant challenges I have experienced, and seen others experience, have come from the people side of the equation and are usually driven by someone's anxiety that may or may not be overtly apparent to everyone else. In challenging situations, I try to lead with the mantra of 'assume best intentions and take the time to understand my partners' perspectives, challenges and concerns and then build common ground, which is usually by aligning on what the larger goal is. From that point of common understanding, we can together find the best way to move things forward productively. Being the kind of partner that people really want to work with, as opposed to one they simply have to work with, results in greater opportunities and a strong network.

\section{How do you manage work/life balance in your busy schedule \& what advice would you like to give to young women who are starting their careers?}

Honestly, it is not really a work/life balance, but more a work/life integration and figuring out what that looks like to enable you to stay energized. For me, learning to prioritize the work and ensuring that time is spent on the most important items every single day, rather than trying to complete the entire to-do list, has been critical. What will make you stand out is not necessarily the absolute volume of work you do, but the quality. I find that women will often work tirelessly to accomplish a great deal, but be so busy doing the work, that they have neglected to appropriately highlight the value they are delivering. You cannot assume that all your efforts will be self-evident. So, it is important to focus on the most important items (not necessarily the most flashy), demonstrate impact, delegate what you can (and should - appropriate delegation provides growth opportunities to others) and remember that you have a long career ahead of you, while some of those special moments at home will only come once.

\section{How would you like to inspire the next generation of girls/women in STEM?}

I think the greatest opportunity to raise the level of science and innovation within our industry will be through developing leadership talent. Too frequently, leadership roles are given to those who are perceived as the most illustrious scientist without appropriate weight given to the importance of leadership capability. I would like to serve as an advocate for development of true scientific leaders. These leaders will not only have scientific expertise, but will also have the ability to assume appropriate risk, make incisive decisions and be able to effectively communicate vision and engage the hearts as well as the minds of those they lead. I believe women have enormous potential in this arena and encourage them to ensure that they develop their leadership skills hand in hand with their scientific skills.

\section{Disclaimer}

The opinions expressed in this interview are those of the interviewee and do not necessarily reflect the views of Future Science Group.

Financial \& competing interests disclosure

The author has no relevant affiliations or financial involvement with any organization or entity with a financial interest in or financial conflict with the subject matter or materials discussed in the manuscript. This includes employment, consultancies, honoraria, stock ownership or options, expert testimony, grants or patents received or pending, or royalties.

No writing assistance was utilized in the production of this manuscript. 